\title{
Visual detection of isothermal nucleic acid amplification using $\mathrm{pH}$-sensitive dyes
}

\author{
Nathan A. Tanner, Yinhua Zhang, and Thomas C. Evans Jr. \\ DNA Enzymes Division, New England Biolabs, Ipswich, MA
}

BioTechniques 58:59-68 (February 2015) doi 10.2144/000114253

Keywords: LAMP; PCR; amplification; detection; molecular diagnostics

Supplementary material for this article is available at www.BioTechniques.com/article/114253.

Nucleic acid amplification is the basis for many molecular diagnostic assays. In these cases, the amplification product must be detected and analyzed, typically requiring extended workflow time, sophisticated equipment, or both. Here we present a novel method of amplification detection that harnesses the $\mathrm{pH}$ change resulting from amplification reactions performed with minimal buffering capacity . In loop-mediated isothermal amplification (LAMP) reactions, we achieved rapid (<30 min) and sensitive (<10 copies) visual detection using pH-sensitive dyes. Additionally, the detection can be performed in real time, enabling high-throughput or quantitative applications. We also demonstrate this visual detection for another isothermal amplification method (strand-displacement amplification), PCR, and reverse transcription LAMP (RT-LAMP) detection of RNA. The colorimetric detection of amplification presented here represents a generally applicable approach for visual detection of nucleic acid amplification, enabling molecular diagnostic tests to be analyzed immediately without the need for specialized and expensive instrumentation.

Nucleic acid amplification is an essential tool in life sciences fields from basic laboratory research to clinical diagnostics. The use of diagnostic nucleic acid amplification has expanded outside of specialized laboratory settings as improvements in cost and amplification techniques have enabled wider access. The key technique for amplification has long been the polymerase chain reaction (PCR), which, although widely used and understood, requires thermal cycling equipment and some mechanism of amplification detection, either through real-time monitoring (e.g., fluorimetry) or post-reaction electrophoresis. Sequence-specific isothermal amplification represents a promising alternative that obviates the need for even basic equipment; examples of this approach include strand-displacement amplification (SDA) (1,2), helicasedependent amplification (HDA) $(3,4)$, and loop-mediated isothermal amplification (LAMP) $(5,6)$.
LAMP in particular has been used in a number of field and point-of-care diagnostics (7-9). LAMP reactions use a strand-displacing DNA polymerase (and reverse transcriptase for RNA targets) with four to six primers, resulting in highly exponential amplification $(5,10)$. This high degree of DNA synthesis facilitates visual detection of positive amplification based on the precipitation of magnesium pyrophosphate. Detection can be performed in real time with a specialized turbidity instrument or by direct visual assessment, although the latter typically requires a long incubation time ( $\geq 60 \mathrm{~min}$ ), and the precipitate can be difficult to see under even ideal conditions (11-13).

Alternative detection methods for nucleic acid amplification use the color change of a metal-sensitive indicator, such as a shift from dark yellow to yellow (calcein) (14), dark blue to blue (hydroxynaphthol blue) (15), or dark blue to light blue (malachite green) (16-17).
The calcein and hydroxynaphthol blue color shifts are difficult to discern by eye. Furthermore, calcein requires inclusion of the ionic form of manganese $(14,18)$, which can inhibit polymerase reactions. Malachite green features an additional color change in the negative reactions, with a change from dark blue to clear (16-17). These indicators require long incubation times (typically $60 \mathrm{~min}$ ) and have been demonstrated with only moderate sensitivity (>100-1000 copies of target) (14-18). Metal-sensitive indicators have been successfully applied in LAMP reactions; however, the concentrations of reaction cofactors and degree of amplification required have so far precluded extension to PCR and other methods. Intercalating nucleic acid dyes can be added to the reactions for real-time and visual detection, but clear visualization requires UV illumination (15).

When a DNA polymerase incorporates a deoxynucleoside triphosphate into the nascent DNA, the released by-products

\section{METHOD SUMMARY}

We present a novel method for visual detection of nucleic acid amplification using the inherent production of protons by DNA polymerases and a pH indicator in a weakly buffered solution. This method enables clear and rapid evaluation of amplification reactions without the need for equipment or hands-on processing. 
include a pyrophosphate moiety and a hydrogen ion. The release of this proton has been the basis of previous detection methods, notably the semiconductor sequencing technology in the lon Torrent platforms (19-21). A version of this $\mathrm{pH}$ sensor was recently used to monitor DNA amplification with LAMP and PCR (22). These studies also demonstrated the ability of a DNA polymerase to perform efficient synthesis in weakly buffered or nonbuffered solutions. We used this enzyme property to perform LAMP reactions in the presence of low concentrations of buffer and observed a significant change from an initial alkaline $\mathrm{pH}$ to a final acidic $\mathrm{pH}$. Such a significant change in $\mathrm{pH}$ presented the possibility of detecting DNA amplification through the use of $\mathrm{pH}$-sensitive indicator dyes, which we present here as a rapid, robust method for detecting LAMP amplification. We also demonstrate the universality of this approach by its detection of PCR and SDA reactions.

\section{Materials and methods}

\section{LAMP reactions}

Unless otherwise indicated, LAMP reactions contained $10 \mathrm{mM}\left(\mathrm{NH}_{4}\right)_{2} \mathrm{SO}_{4}$, $50 \mathrm{mM} \mathrm{KCl}, 8 \mathrm{mM} \mathrm{MgSO}_{4}, 1.4 \mathrm{mM}$ dNTPs, and $0.1 \% \mathrm{~V} / \mathrm{v}$ Tween-20 and were incubated at $65^{\circ} \mathrm{C}$. All components were mixed in water, and $1 \mathrm{M}$ $\mathrm{KOH}$ was used to adjust the $\mathrm{pH}$ to 8.8-9.0, as measured by $\mathrm{pH}$ paper (colorpHast; EMD Millipore, Billerica, $\mathrm{MA}$ ) or a $\mathrm{pH}$ meter. For low initial $\mathrm{pH}$ reactions (bromocresol purple), $\mathrm{pH}$ was adjusted to 7.5; for high-pH reactions (thymol blue, naphtholphthalein) $\mathrm{pH}$ was adjusted to 10.0. Immediately before reaction, primers (sequences in Supplementary Table S1) were added at the following concentrations (as described in Reference 23): $1.6 \mu \mathrm{M}$ FIP/BIP, $0.2 \mu \mathrm{M}$ F3/B3, and $0.4 \mu \mathrm{M}$ LoopF/B. Template DNA was $5 \mathrm{ng}$ lambda DNA (New England Biolabs, Ipswich, MA), 8.25 ng Caenorhabditis elegans genomic DNA (prepared by Y.Z.), or 10 pg-100 ng (as indicated) HeLa genomic DNA (New England Biolabs). Bst DNA polymerase, Large Fragment or Bst 2.0 DNA polymerase (New England Biolabs) at $0.32 \mathrm{U} / \mu \mathrm{L}$ proved effective, but all displayed data were obtained using Bst 2.0 DNA polymerase because of its more rapid amplification times (23). Both standard ( $8 \mathrm{U} / \mu \mathrm{L}$ stock) and high (120 $\mathrm{U} / \mu \mathrm{L}$ ) polymerase concentrations were effective in $\mathrm{pH}$-detected reactions, but all colorimetric data shown were obtained using the higher concentration enzyme to minimize buffer carryover (i.e., $26 \mu \mathrm{M}$ Tris vs. $400 \mu \mathrm{M}$ ). For RT-LAMP, identical conditions were used with the addition of $0.3 \mathrm{U} / \mu \mathrm{L} R T \mathrm{R}$ reverse transcriptase (New England Biolabs) and 10 ng Jurkat total RNA (BioChain, Newark, CA) as substrate. All solutions of primers, dNTPs, and template DNAs were prepared in water to minimize buffer carryover (except HeLa DNA 0.1 mg/ $\mathrm{mL}$ stock for the highest template input). No betaine was added to the reaction buffer because it was not beneficial to amplification of the targets used here $(23,24)$. All reactions were repeated at least once and were typically performed in triplicate.

\section{Colorimetric pH detection}

All indicator dyes were obtained from Sigma-Aldrich (St. Louis, MO) and made into $50 \mathrm{mM}$ stocks in water (or ethanol for naphtholphthalein), diluted to 2.5 $\mathrm{mM}(25 \times)$ in water, and $\mathrm{pH}$ adjusted above the indication threshold. Dye was added to the reaction mixture and visually inspected to check initial $\mathrm{pH}$, and an image was recorded using a photo scanner. Reactions were incubated at $65^{\circ} \mathrm{C}$ for the indicated time, visually inspected for color change after removal from reaction temperature, and scanned. For fluorescence measurement, 2',7'-bis-(2-carboxyethyl)-5-(and 6)-carboxyfluorescein, acetoxymethyl ester (BCECF-AM) and 5-(and 6)-carboxy SNARF-1 (Life Technologies, Carlsbad, $\mathrm{CA})$ were diluted in water to $50 \mu \mathrm{M}$ and $250 \mu \mathrm{M}$, respectively, and added immediately before the reaction was initiated. Real-time fluorescence was measured using a Bio-Rad (Hercules, CA) CFX96 Touch instrument with plate reads every 15 s. Channel 1 (FAM) was used to record BCECF-AM, and channels 2 (HEX) and 3 (ROX) were used to record the lowand high-pH forms of SNARF-1. Three raw (without background subtraction) fluorescence curves for each sample were averaged and then background corrected using initial (SNARF-1 low pH) or final (BCECF-AM, SNARF-1 high pH) fluorescence values for presentation.

\section{PCR}

PCR was performed in a $50 \mu \mathrm{L}$ reaction containing $50 \mathrm{mM} \mathrm{KCl,} 2 \mathrm{mM} \mathrm{MgCl}_{2}, 0.3$ mM dNTPs, and $0.075 \mathrm{U} / \mu \mathrm{L}$ Taq DNA polymerase (New England Biolabs), with $\mathrm{pH}$ adjusted to $\sim 8.5$ with $1 \mathrm{M} \mathrm{KOH}$. Reactions were incubated at $95^{\circ} \mathrm{C}$ for 2 min followed by 40 cycles of $95^{\circ} \mathrm{C}$ for $10 \mathrm{~s}, 58^{\circ} \mathrm{C}$ for $15 \mathrm{~s}$, and $68^{\circ} \mathrm{C}$ for $30 \mathrm{~s}$. Amplified target was a $1287 \mathrm{bp}$ fragment from pAll17 plasmid DNA (a gift from W. Jack, New England Biolabs). Amplification was detected using $100 \mu \mathrm{M}$ phenol red and confirmed with $1 \%$ agarose gel electrophoresis.

\section{SDA}

SDA was performed in a solution containing $10 \mathrm{mM}\left(\mathrm{NH}_{4}\right)_{2} \mathrm{SO}_{4}, 50 \mathrm{mM}$ $\mathrm{KCl}, 8 \mathrm{mM} \mathrm{MgSO}_{4}, 0.4 \mathrm{mM}$ dATP/dGTP/ dTTP, and $0.8 \mathrm{mM}$ 2'-deoxycytidine-5'O-(1-thiotriphosphate) (dCTP- $\alpha \mathrm{S}$; Trilink Biotechnologies, San Diego, CA), with the $\mathrm{pH}$ adjusted to $~ 8.5$ with $1 \mathrm{M} \mathrm{KOH}$. Reactions contained $0.5 \mu \mathrm{M}$ each of forward and reverse SDA and Bump primers designed to target the human BRCA1 gene (Supplementary Table S1), along with $100 \mathrm{ng}$ HeLa genomic DNA, $0.32 \mathrm{U} / \mu \mathrm{L}$ Bst 2.0 DNA polymerase, and $0.2 \mathrm{U} / \mu \mathrm{L}$ BsoBI (New England Biolabs). Indicator dyes were included at 100 $\mu \mathrm{M}$ as described, and reactions were incubated at $65^{\circ} \mathrm{C}$.

\section{Results and discussion}

We investigated the behavior of LAMP DNA polymerases (Bst DNA polymerase, Large Fragment and Bst 2.0 DNA polymerase) in minimal buffering conditions and observed a wide range of $\mathrm{pH}$ tolerance, with efficient LAMP reactions occurring within a $\mathrm{pH}$ range of 6.0-10.0. To determine the drop in $\mathrm{pH}$ caused by LAMP amplification, we measured the reaction $\mathrm{pH}$ before initiation and after completion and observed a significant drop in $\mathrm{pH}$, from the initial value of approximately $\mathrm{pH} 8.8$ to a final value of pH 6.0-6.5 (Figure 1A). The pH tolerance of LAMP reactions and this $>2 \mathrm{pH}$ unit decrease enables, in theory, the use of $\mathrm{pH}$ indicator dyes to monitor amplification success in LAMP reactions. There are many commercially available $\mathrm{pH}$ indicator dyes that have easily discernable color transitions in the neutral range (Supplementary Table S2). For visual detection, 
A

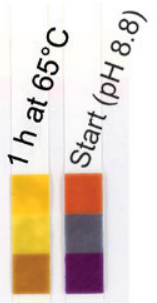

$\mathrm{pH}$ Key

\begin{tabular}{|l|lllllllllll}
5.0 & 5.5 & 6.0 & 6.5 & 7.0 & 7.5 & 8.0 & 8.5 & 9.0 & 9.5 & 10.0
\end{tabular} (1)

B

B

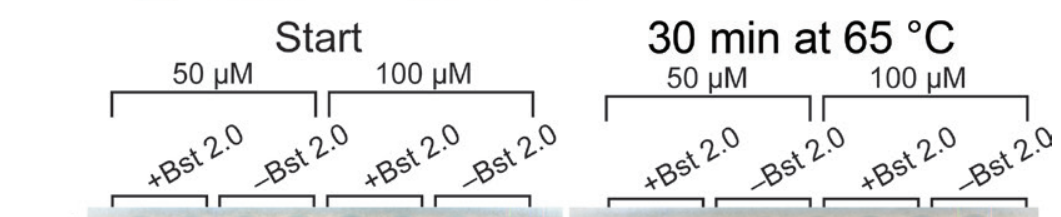

$\mathrm{pH} 8.8$ and changing to the low-pH color rapidly in reactions. Many other indicators are available, but their color transitions occur in $\mathrm{pH}$ ranges not well suited for DNA polymerase reactions. Examples are shown in Supplementary Figure S2, with dyes that require a higher (>pH 9.5) initial $\mathrm{pH}$ for clear indication (e.g., naphtholphthalein, thymol blue) or a lower initial $\mathrm{pH}(\mathrm{pH} 7.5)$ to reach the necessary $\mathrm{pH}$ transition zone. These dyes were usable but required longer reaction times, likely because of the larger $\mathrm{pH}$ changes needed to reach transition and suboptimal polymerase performance at the $\mathrm{pH}$ range extremes. Thus, we preferred the dyes shown in Figures 1-3 (phenol red, cresol red, neutral red, m-cresol purple). Reactions without DNA polymerase remained at the high-pH indicator color, demonstrating that, although not buffered or degassed, the solution's $\mathrm{pH}$ is sufficiently stable during a lengthy incubation at $65^{\circ} \mathrm{C}$ to retain the initial indicator color. We observed that a small reaction volume (25 $\mu \mathrm{L}$ ), sealed vessels, and weak buffering ( $26 \mu \mathrm{M}$ Tris) were sufficient to maintain $\mathrm{pH}$ without enzyme through at least a 2 hour $65^{\circ} \mathrm{C}$ incubation followed by overnight storage at room temperature.

Having demonstrated that $\mathrm{pH}$ indicator dyes are compatible with LAMP reactions, we next examined the effect of background or nontemplate amplification. LAMP, although highly specific in regards to template sequence recognition, can result in substantial nontemplate amplification depending on reaction conditions and primers (25). Figure $2 \mathrm{~A}$ shows the specificity of the $\mathrm{pH}$ change during amplification using two amplicons that display nontemplate amplification when assayed using other detection methods. Both primer sets for the detection of C. elegans lec-10 and human BRCA1 showed a $\mathrm{pH}$ drop in positive reactions in under $15 \mathrm{~min}$, but negative control reactions maintained the initial reaction color. Extending the incubation time to 60 min resulted in some color change that we attribute to nontemplate amplification, with an intermediate color change visible in some control reactions. These results demonstrate that $\mathrm{pH}$ detection performs similarly to other methods in regards to nontemplate amplification,

but even when primer design and optimi- a $\mathrm{pH} 8.8$ solution containing only a small amount of Tris- $\mathrm{HCl}$ carried over from the
DNA polymerase storage buffer $(10 \mathrm{mM}$ Tris- $\mathrm{HCl}$ in the enzyme storage buffer, $25-400 \mu \mathrm{M}$ the in final reaction). Figure IB shows reactions at setup, with the specific dye and the starting $\mathrm{pH}$. After a 30 min incubation at $65^{\circ} \mathrm{C}$, reactions containing DNA polymerase displayed color changes, such as red to yellow (phenol red, cresol red) or faint orange to pink (neutral red). These results showed that indicator dyes were amenable to standard LAMP conditions with minimal buffering, indicating strongly at initial 
A

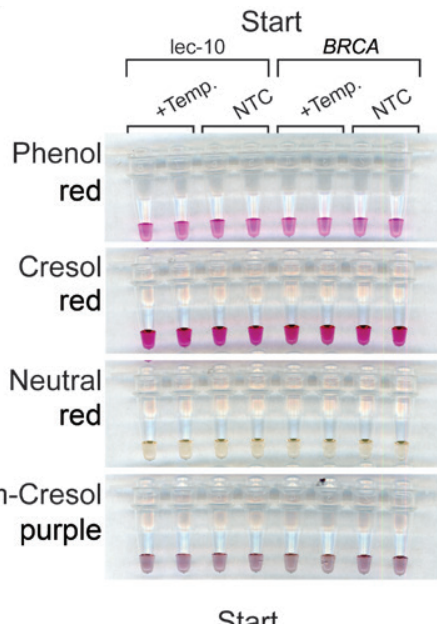

Start

ng DNA:

Phenol

red

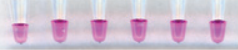

Cresol

red

00000

Neutral

red

m-Cresol purple
$15 \mathrm{~min}$ at $65^{\circ} \mathrm{C}$

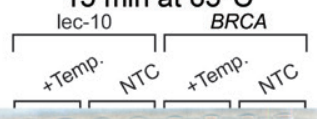

$-100.00$
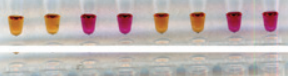

000000

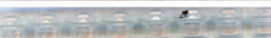

4.0 .000

15 min
00000000

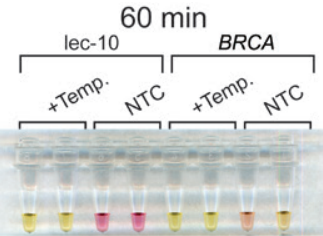

0.0000000

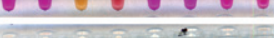

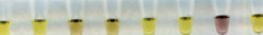

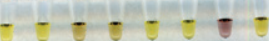

$30 \mathrm{~min}$

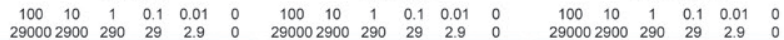

0.0000

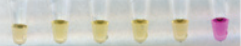

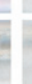

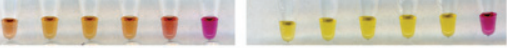

00000000000

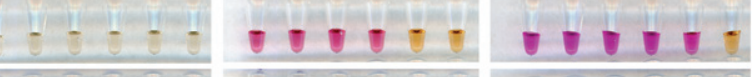

00000

Figure 2. Specificity and sensitivity of colorimetric detection. (A) Specificity of $\mathrm{pH}$ amplification detection. Loop-mediated isothermal amplification (LAMP) reactions with either 1 ec- 10 primers and Caenorhabditis elegans DNA or BRCA1 primers and HeLa genomic DNA. All reactions contained $8 \mathrm{U}$ Bst 2.0 DNA polymerase, were $\mathrm{pH} 8.8$ ( $26 \mu \mathrm{M}$ Tris) at initiation, and were incubated for $60 \mathrm{~min}$ at $65^{\circ} \mathrm{C}$. At $15 \mathrm{~min}$, a $\mathrm{pH}$-induced color change was apparent in all positive reactions, but nontemplate controls (NTCs) remained the starting color. After $60 \mathrm{~min}$, positive reactions showed increased color change, and some intermediate change was observed in NTCs. (B) Sensitivity of $\mathrm{pH}$ amplification detection. LAMP reactions with cystic fibrosis transmembrane conductance regulator gene (CFTR) primers and various amounts of HeLa genomic DNA as indicated were incubated for 30 min at $65^{\circ} \mathrm{C}$. At $15 \mathrm{~min}$, a $\mathrm{pH}$-induced color change was clearly seen in reactions with higher template concentrations or those containing m-cresol purple (excluding the nontemplate control). By 30 min, reactions at all template concentrations exhibited color changes indicative of amplification. For all dyes, the nontemplate control remained at the initial high $\mathrm{pH}$ color after $30 \mathrm{~min}$ of incubation.

\section{Introducing the next generation of flasks, dishes and plates}

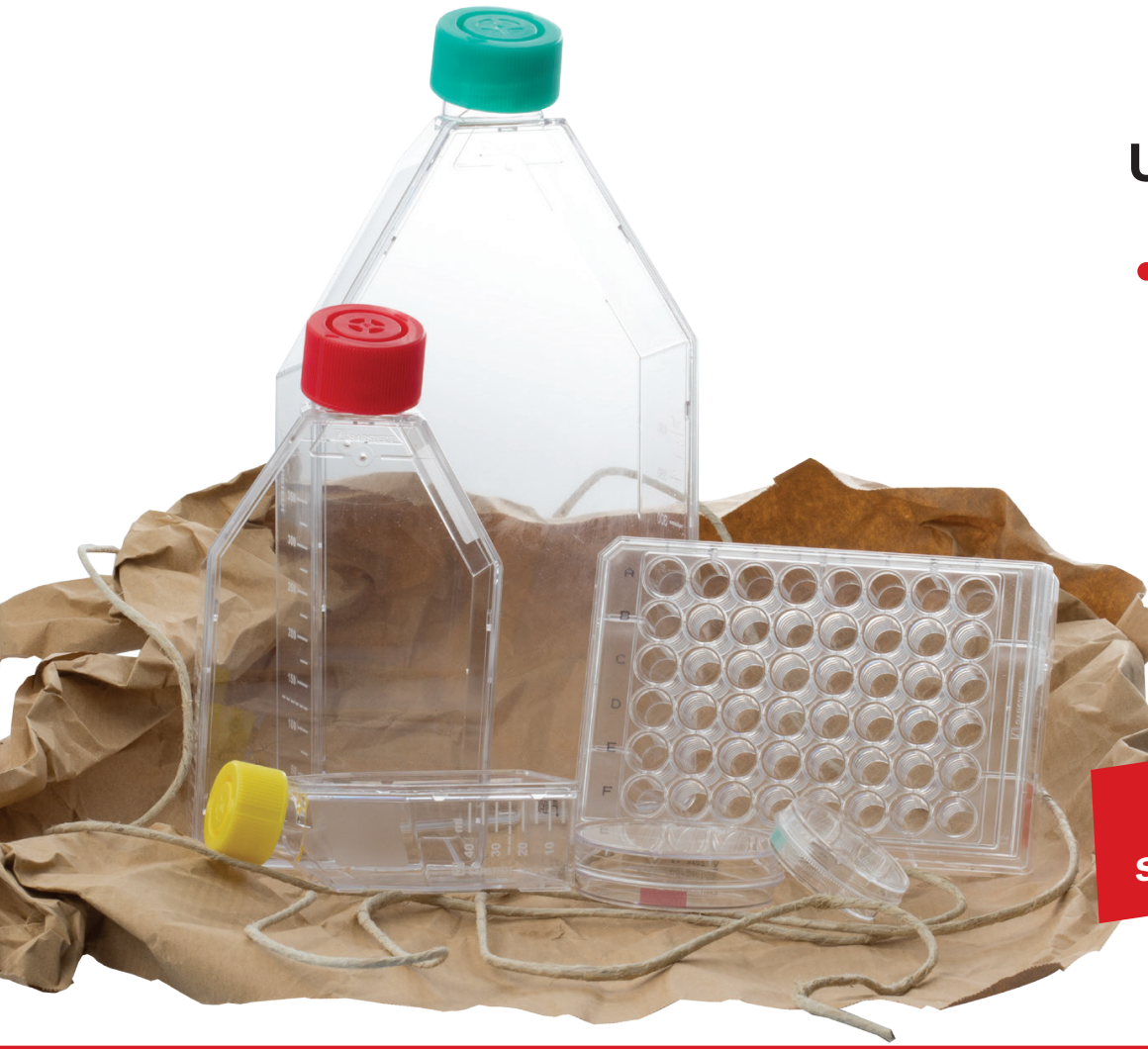

Updated for:

- superior growth

- economic handling

- traceabilty 

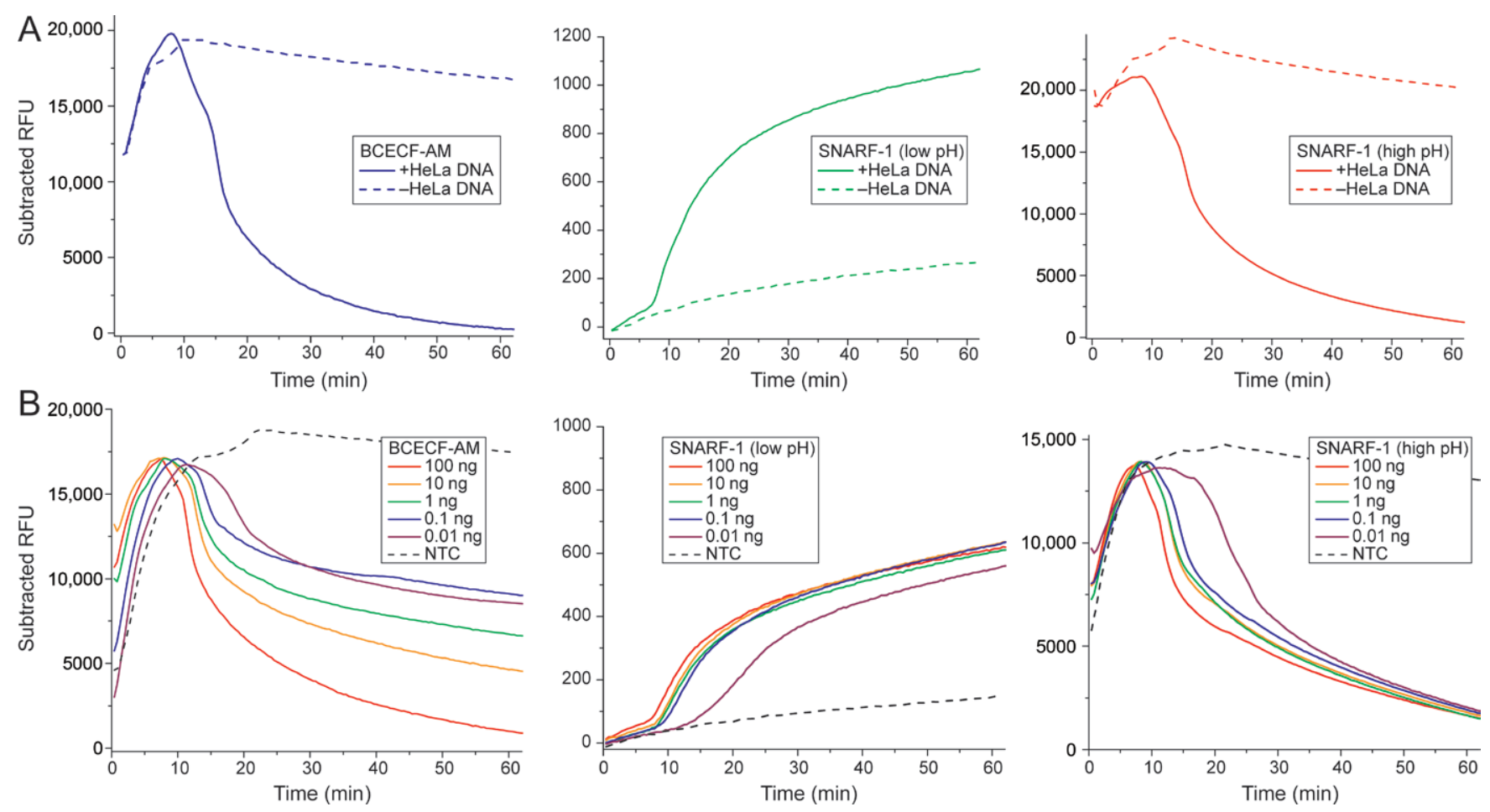

Figure 3. Real-time detection of $\mathrm{pH}$ change during loop-mediated isothermal amplification (LAMP) reactions. (A) LAMP reactions performed with BRCA1 primers and $100 \mathrm{ng}$ HeLa DNA with either BCECF-AM or SNARF-1 fluorescent indicator. Fluorescence change was observed in positive reactions, while nontemplate reactions exhibited only background drift. BCECF-AM and the high-pH form of SNARF-1 (ROX channel) showed loss of signal, while the low-pH form of SNARF-1 showed gain although with approximately 10-fold lower fluorescent counts (plotted as relative fluorescent units, RFU). (B) Reactions with cystic fibrosis transmembrane conductance regulator gene (CFTR) primers and the indicated amounts of HeLa genomic DNA showed fluorescence changes at all template amounts, while the nontemplate controls (NTCs) showed only background changes. While all template amounts were amplified rapidly, clear distinction between each amount was observed across the 5-order concentration range.

zation cannot be performed, the amplification time differential in the positive and negative reactions is sufficient to allow discrimination.

The potential reaction sensitivity when using $\mathrm{pH}$ indicator dyes is shown in Figure 2B, where a range of HeLa DNA amounts (0.01-100 ng; 3-30,000 copies) was detected using primers for the cystic fibrosis transmembrane conductance regulator gene (CFTR). After $15 \mathrm{~min}$, all template concentrations above $10 \mathrm{pg}$ ( $\sim 3$ copies) were clearly detected with an intermediate change seen for the reactions containing 10 pg of DNA. After 30 min, all concentrations indicated amplification, but the nontemplate controls ( 0 ng input DNA) remained at the starting reaction color. This 5 order-of-magnitude dynamic range covers typical test DNA amounts and demonstrates a clear, robust amplification signal visible by eye for samples containing as little as 2-3 copies of the target in under $30 \mathrm{~min}$ and under $15 \mathrm{~min}$ for template amounts above 10 copies.

Although LAMP has useful characteristics and is a reliable amplification method, numerous other technologies are widely used, including the most popular method, PCR. Therefore, we tested the $\mathrm{pH}$ indicator dye method for applicability to PCR and SDA reactions. Supplementary Figure S3A shows a pH indicator dye color change in low-buffer PCR amplifying a 1287 bp fragment from plasmid DNA in the presence of phenol red. Supplementary Figure S3B shows a color change in low-buffer SDA reactions amplifying a region of the BRCA1 gene with three $\mathrm{pH}$ dyes. As shown, both methods produced clear changes in color because of a drop in $\mathrm{pH}$. However, PCR reactions were prone to a background $\mathrm{pH}$ drop caused by thermal cycling, but using cap-sealed PCR tubes and 25 $\mu \mathrm{L}$ of mineral oil mitigated this problem and enabled consistent colorimetric $\mathrm{pH}$ detection. SDA required $>30 \mathrm{~min}$ to observe a clear color change, and PCR needed $>20$ cycles even with $\sim 10^{6}$ copies of input target DNA compared with LAMP reactions, which displayed a $\mathrm{pH}$ drop in $<10 \mathrm{~min}$. We observed for PCR a dependence of color change on amplicon length: amplification of products $<500 \mathrm{bp}$ did not produce a color change even with 40 cycles of PCR, whereas amplification of longer (1.2-10 kb) products produced a robust color change (data not shown). This is evidence that the amount of DNA synthesis, and thus proton release, determines the magnitude of the drop in $\mathrm{pH}$ in weakly buffered amplification reactions. These additional constraints and considerations for PCR reactions indicate that our detection method is best suited to isothermal amplification.

We also sought to demonstrate colorimetric $\mathrm{pH}$ detection of amplification from an RNA template, using RT-LAMP as an example method. Using primers for human hydroxymethylbilane synthase gene (Supplementary Table S1), Bst 2.0 DNA polymerase, and the reverse transcriptase $R T x$, we ran one-step RT-LAMP reactions with 10 ng Jurkat total RNA. Reactions were heated directly to $65^{\circ} \mathrm{C}$ and incubated for $30 \mathrm{~min}$, and color change was detected in the presence of neutral red and RNA but not in reactions lacking RNA (Supplementary Figure S3C). This indicates that RTx was active in low-buffer reactions and further 
demonstrates the applicability of colorimetric $\mathrm{pH}$ detection to various amplification methods, whether RNA or DNA templates are used as amplification targets.

As an alternative to visual detection, we examined real-time detection of the nonbuffered LAMP reactions using a 96-well plate format amenable to quantitative or high-throughput applications. We used fluorescent $\mathrm{pH}$ indicators that were observed to have $\mathrm{pH}$-dependent spectral shifts at LAMP temperatures (BCECF-AM and SNARF-1). These dyes have $\mathrm{pK}_{\mathrm{a}}$ values of $\mathrm{pH} 6.98$ and 7.5 , respectively, which are close to neutral $\mathrm{pH}$, and exhibit robust fluorescence changes (>10-fold) through pH 6.0-9.0 (Supplementary Figure S4). BCECF-AM exhibits high fluorescence at high $\mathrm{pH}\left(\lambda_{\text {ex }} / \lambda_{\text {em }}\right.$ at $\left.\mathrm{pH} 9500 / 530 \mathrm{~nm}\right)$, which decreases with decreasing $\mathrm{pH}$, but SNARF-1 shifts its excitation/emission maxima from $575 / 650 \mathrm{~nm}$ (pH 9) to 525/590 $\mathrm{nm}$ (pH6), enabling both a loss- and gain-ofsignal fluorescent detection. We measured BCECF-AM fluorescence using the SYBR/ FAM channel of a CFX-96 real-time PCR instrument and SNARF-1 using the HEX/ TET (low-pH) and ROX/TexasRed (high-pH) channels. Performing low-buffer LAMP with $2 \mu \mathrm{M}$ BCECF-AM resulted in a fluorescence decrease of $>10,000$ counts, with a rapid drop in signal at $\sim 10 \mathrm{~min}$ (Figure $3 \mathrm{~A}$ ), matching the threshold times observed using SYTO-9 or turbidity detection. Reactions with SNARF-1 gave a fluorescence decrease of $>15,000$ counts in the ROX (high-pH) channel and a gain of 1000 counts in the HEX (low-pH) channel. Normalizing curves to maximum fluorescence shows a concomitant change in the two signals (Supplementary Figure S5), indicating that either channel or $\mathrm{pH}$ form can be used for SNARF-1. Figure 3A shows negative control reactions, which showed only background $\mathrm{pH}$ changes compared with the rapid and significant change of the positive reactions. The sensitivity of this detection is shown in Figure $3 \mathrm{~B}$, with 10 pg of HeLa DNA ( 3 copies) detected in $<15$ min (CFTR primers), consistent with the visual detection shown in Figure 2B. Together, these data demonstrate that the $\mathrm{pH}$ change of LAMP reactions can be monitored in real time. For real-time detection, we used the lower stock concentration $(8000 \mathrm{U} / \mathrm{mL})$ of DNA polymerase that is commercially available, resulting in carryover of $0.4 \mathrm{mM}$ Tris. Reactions with 100 ng HeLa DNA also carried over 0.4 mM Tris; thus, the high template input condition contained $0.8 \mathrm{mM}$ Tris but still demonstrated a robust $\mathrm{pH}$ change at $\sim 10$ min consistent with a linear response to input amount. Although buffer concentration is important for detecting amplification in these reactions and should be kept at a minimum, these results demonstrate flexibility of input to buffered components, where the amount of carried-over buffer can exceed $0.5 \mathrm{mM}$.

Isothermal amplification techniques such as LAMP offer the promise of nucleic acid diagnostics with simplified instrumentation, or none at all (7). One advantage of LAMP is the ability to detect reactions by eye, facilitating field, point-of-care, and even basic rapid laboratory detection $(8,9)$. However, previously published methods have required long incubation times using either difficultto-see precipitation or subtle changes in the color of an indicator (11,13-18). As demonstrated here, a robust and rapid alternative for visual detection is monitoring the $\mathrm{pH}$ drop in the reaction mixture with indicator dyes. LAMP reactions are capable of producing a 2-3 $\mathrm{pH}$ unit drop without loss of reaction efficiency in very weakly buffered solutions.

\section{Sometimes it takes more than one slice to make a great sandwich.}

\section{The SageELF ${ }^{\mathrm{Tm}}$ from Sage Science.}

\section{Automated whole sample size fractionation for proteomic studies.}

\section{Collect multiple slices from protein samples.}

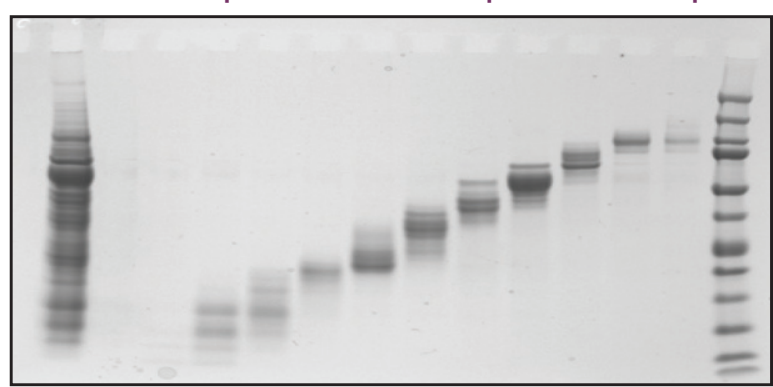

The SageELF automatically
size-separates protein
samples, and then collects
fractions in 12 contiguous
buffer-filled wells.

Reduce sample complexity upstream of protein mass spectrometry.

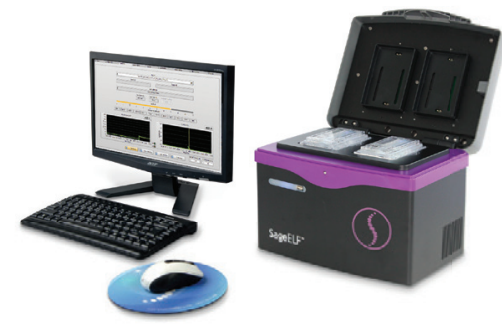

sage science

www.sagescience.com 
This $\mathrm{pH}$ change is sufficient to enable the use of neutral-range transition $\mathrm{pH}$ indicator dyes, which are low-priced, simple to use, and exhibit easy-to-see color changes. Because this detection method responds directly to the release of protons, a natural consequence of any polymerase-catalyzed amplification reaction, it can be applied to many amplification methods, as demonstrated here with the isothermal methods LAMP, RT-LAMP, and SDA; detection in PCR is possible but is more limited compared with the isothermal techniques. Detection of amplification through $\mathrm{pH}$ change may not be suitable for all methodologies; for example, in helicase-dependent amplification (HDA), which includes enzymes that catalyze nucleotide hydrolysis, a drop in $\mathrm{pH}$ may occur because of helicase activity decoupled from amplification.

In general, isothermal amplification reactions have characteristics well suited for facilitating point-of-care and field applications, such as no requirement for a thermocycler, rapid amplification, and tolerance of inhibitors. However, the methods of detection in current use limit this potential to laboratory settings or require instrumentation for reliable analysis. The low cost, ease of visualization without instruments, and flexibility of the $\mathrm{pH}$ sensitive indicator dyes may allow the promise of isothermal amplification technologies to be fully realized. The method presented here enables easy visual detection of an amplification reaction without any requirement beyond heating to reaction temperature; for room temperature reactions (e.g., recombinase-polymerase amplification) (26), no equipment would be required at all. Future studies will investigate the feasibility of using minimally processed samples with low-buffer LAMP reactions, but the variety of indicator dyes available and the tolerance of our assay for up to $\sim \mathrm{mM}$ of a wide $\mathrm{pH}$ range buffer (such as Tris) already provides flexibility in designing compatible nucleic acid amplification reactions. In summary, the use of colorimetric visualization of amplification by detecting $\mathrm{pH}$ changes could further the use of amplification as a molecular diagnostic tool, enabling field diagnostics with clear, rapid, and robust visual detection.

\section{Author contributions}

N.T. and T.C.E. conceived the method and designed the experiments. N.T. and
Y.Z. performed the experiments. N.T., Y.Z., and T.C.E. wrote the manuscript.

\section{Acknowledgments}

The authors thank Gregory Lohman and Andrew Gardner for a critical reading of the manuscript and New England Biolabs for material and financial support.

\section{Competing interests}

The authors are employed by New England Biolabs, manufacturer of the amplification reagents described in this manuscript, and have filed a patent application describing this method.

\section{References}

1. Walker, G.T., M.S. Fraiser, J.L. Schram, M.C. Little, J.G. Nadeau, and D.P. Malinowski. 1992. Strand displacement amplification-an isothermal, in vitro DNA amplification technique. Nucleic Acids Res. 20:1691-1696.

2. Spargo, C.A., M.S. Fraiser, M. Van Cleve, D.J. Wright, C.M. Nycz, P.A. Spears, and G.T. Walker. 1996. Detection of M. tuberculosis DNA using thermophilic strand displacement amplification. Mol. Cell. Probes 10:247-256.

3. Vincent, M., Y. Xu, and H. Kong. 2004. Helicasedependent isothermal DNA amplification. EMBO Rep. 5:795-800.

4. An, L., W. Tang, T.A. Ranalli, H.J. Kim, J. Wytiaz, and H. Kong. 2005. Characterization of a thermostable UvrD helicase and its participation in helicase-dependent amplification. J. Biol. Chem. 280:28952-28958.

5. Notomi, T., H. Okayama, H. Masubuchi, T. Yonekawa, K. Watanabe, N. Amino, and T. Hase. 2000. Loop-mediated isothermal amplification of DNA. Nucleic Acids Res. 28:E63.

6. Nagamine, K., K. Watanabe, K. Ohtsuka, T. Hase, and T. Notomi. 2001. Loop-mediated isothermal amplification reaction using a nondenatured template. Clin. Chem. 47:1742-1743.

7. Gill, P. and A. Ghaemi. 2008. Nucleic acid isothermal amplification technologies: a review. Nucleosides Nucleotides Nucleic Acids 27:224243.

8. Niemz, A., T.M. Ferguson, and D.S. Boyle. 2011. Point-of-care nucleic acid testing for infectious diseases. Trends Biotechnol. 29:240-250.

9. Tomlinson, J. 2013. In-field diagnostics using loop-mediated isothermal amplification. Methods Mol. Biol. 938:291-300.

10. Nagamine, K., T. Hase, and T. Notomi. 2002. Accelerated reaction by loop-mediated isothermal amplification using loop primers. Mol. Cell. Probes 16:223-229.

11. Mori, Y., K. Nagamine, N. Tomita, and T. Notomi. 2001. Detection of loop-mediated isothermal amplification reaction by turbidity derived from magnesium pyrophosphate formation. Biochem. Biophys. Res. Commun. 289:150-154.

12. Mori, Y., M. Kitao, N. Tomita, and T. Notomi. 2004. Real-time turbidimetry of LAMP reaction for quantifying template DNA. J. Biochem. Biophys. Methods 59:145-157.
13. Zhang, F., L. Ma, Z. Xu, J. Zheng, Y. Shi, Y. Lu, and Y. Miao. 2009. Sensitive and rapid detection of Karenia mikimotoi (Dinophyceae) by loop-mediated isothermal amplification. Harmful Algae. 8:839-842.

14. Tomita, N., Y. Mori, H. Kanda, and T. Notomi. 2008. Loop-mediated isothermal amplification (LAMP) of gene sequences and simple visual detection of products. Nat. Protoc. 3:877-882.

15. Goto, M., E. Honda, A. Ogura, A. Nomoto, and K. Hanaki. 2009. Colorimetric detection of loopmediated isothermal amplification reaction by using hydroxy naphthol blue. Biotechniques 46:167-172.

16. Jothikumar, P., J. Narayanan, and V.R. Hill. 2014. Visual endpoint detection of Escherichia coli 0157:H7 using isothermal Genome Exponential Amplification Reaction (GEAR) assay and malachite green. J Microbiol. Methods. 98:122-127.

17. Nzelu, C.O., E.A. Gomez, A.G. Cáceres , T, Sakurai , L. Martini-Robles, H. Uezato, T. Mimori, K. Katakura, et al. 2014. Development of a loop-mediated isothermal amplification method for rapid mass-screening of sand flies for Leishmania infection. Acta Trop. 132:1-6.

18. Arimatsu, Y., S. Kaewkes, T. Laha, S. Hong, and B. Sripa. 2012. Rapid detection of Opisthorchis viverrini copro-DNA using loop-mediated isothermal amplification. Parasitol. Int. 61:178-182.

19. Pourmand, N., M. Karhanek, H.H.J. Persson, C.D. Webb, T.H. Lee, A. Zahradnikova, and R.W. Davis. 2006. Direct electrical detection of DNA synthesis. Proc. Natl. Acad. Sci. USA 103:6466-6470.

20. Purushothaman, S., C. Toumazou, and C. Ou. 2006. Protons and single nucleotide polymorphism detection: a simple use for the lon Sensitive Field Effect Transistor. Sens. Actuators B Chem. 114:964-968.

21. Rothberg, J.M., W. Hinz, T.M. Rearick, J. Schultz, W. Mileski, M. Davey, J.H. Leamon, K. Johnson, et al. 2011. An integrated semiconductor device enabling non-optical genome sequencing. Nature 475:348-352.

22. Toumazou, C., L.M. Shepherd, S.C. Reed, G.I. Chen, A. Patel, D.M. Garner, C.J. Wang, C.P. Ou, et al. 2013. Simultaneous DNA amplification and detection using a $\mathrm{pH}$-sensing semiconductor system. Nat. Methods 10:641-646.

23. Tanner, N.A., Y. Zhang, and T.C. Evans, Jr. 2012 Simultaneous multiple target detection in real-time loop-mediated isothermal amplification. Biotechniques 53:81-89.

24. Tanner, N.A. and Evans, T.C. Jr. (2014) Loopmediated isothermal amplification for detection of nucleic acids. Curr Protoc Mol Biol. 105:Unit 15.14.

25. Kimura, Y., M.J.L. de Hoon, S. Aoki, Y. Ishizu, Y. Kawai, Y. Kogo, C.O. Daub, A. Lezhava, et al. 2011. Optimization of turn-back primers in isothermal amplification. Nucleic Acids Res. 39:e59.

26. Piepenburg, O., C.H. Williams, D.L. Stemple, and N.A. Armes. 2006. DNA detection using recombination proteins. PLoS Biol. 4:e204.

Received 26 September 2014; accepted 20 November 2014.

Address correspondence to Thomas C. Evans Jr., DNA Enzymes Division, New England Biolabs, Ipswich, MA. E-mail: evans@neb.com

To purchase reprints of this article, contact: biotechniques@fosterprinting.com 